\title{
The Technical Performance and Interpretation of Results from a Large Scale Na-silicate Gel Treatment of a Production Well on the Gullfaks Field
}

\author{
T.A.T. Lund, H.I. Berge, S. Espedal, R. Kristensen, T.A. Rolfsvåg and G. Strømsvik \\ Statoil, P.O.Box 300 Forus, N-4001 Stavanger, Norway
}

\section{ABSTRACT}

The development program for processes to reduce watercut during production of the lower Brent reservoir unit of the Gullfaks field culminated by a large scale injection of alkaline Na-silicate gel in a lower Brent production well during summer 1993. The operation was prepared and designed through an extensive laboratory program as well as small scale onshore field tests.

The injection sequence consisted of a preflush of fresh water added low concentrations of $\mathrm{KCl}$ or Na-silicate. The purpose of the preflush was to condition reservoir parameters to improve injectivity of the Na-silicate gel. A volume of approximately $5500 \mathrm{~m}^{3} 4-6 \% \mathrm{Na}$-silicate gel was injected and displaced into the reservoir with one tubing volume fresh water. In total $9700 \mathrm{~m}^{3}$ fluid was injected. An extensive sampling and analysis program of production fluids was worked out and results will be presented.

Analysis of ion composition of the produced water allowed to determine the fractions of sea water, formation water and fresh water used as solvent for the injected fluids. After treatment, the fraction of fresh water was initially about $50 \%$, rapidly raising to $90 \%$ and higher. The injected volume was backproduced during a period of about five months. The reduction of permeability of the treated volume was also observed as an increased draw-down in the well. The results show that permeability is reduced significantly in the treated volume, and that an efficient water diversion has been achieved. The water-cut was initially at the same level as before treatment, but decreased within three months to $72-74 \%$. The water-cut stayed at this level for another three months before rising to $77 \%$. The treatment gave initially an increase in sand production and the well had temporarily to be produced at reduced rates. After this initial period, the total fluid rate could be increased to about $2000 \mathrm{Sm}^{3} / \mathrm{d}$, the same level as before treatment, implying that the oil rate has been significantly higher most of the period after treatment than before.

Based on history matching of the reservoir section with the Eclipse black oil simulator, predictions of well performance after treatment were made. The history matching included an active use of well influx data, including results from four production logs. The result indicated that the oil saturation in the drainage volume of the well was rather low at the time of treatment. Predictions with the history matched model reconstructed the water-cut development, and an estimate of incremental oil production can be done by comparing with predictions of well productivity without gel treatment. Using the fresh water as tracer, the permeability reduction factor in the treated volume is calculated to be approximately hundred.

The conclusion is that a further testing and application of the technology in North Sea reservoirs seems to be very promising for the pupose of improving oil recovery and well productivity.

submitted to the 8th European Sumposium on Improved Oil Recovery.

15-17 May 1995, Vienna, Austria

!: Full Paper to be distributed at the Symposium !! 